\title{
Effects of Breast Cancer and Type 2 Diabetes Mellitus on Ventilation Volumes and Pressures in Adult Women
}

Rodrigo Muñoz Cofré ${ }^{1}$, Mariano del Sol ${ }^{1}$, Gonzalo Palma Rozas ${ }^{2}$, Washington Valverde Ampai ${ }^{3}$, Daniel Conei Valencia ${ }^{1,4}$, Gabriel Nasri Marzuca-Nassr ${ }^{5}$, Paul Medina González ${ }^{6}$ \& Máximo Escobar Cabello $^{6}$

1. Programa de Doctorado en Ciencias Morfológicas, Universidad de La Frontera, Temuco, Chile.

2. Hospital Clínico Pontificia Universidad Católica, Santiago, Chile.

3. Programa de Magíster en Ciencias Fisiológicas Universidad Finis Terrae, Santiago, Chile.

4. Departamento de Ciencias Morfológicas, Facultad de Medicina y Ciencia, Universidad San Sebastián, Puerto Montt, Chile.

5. Departamento de Medicina Interna, Facultad de Medicina, Universidad de La Frontera, Temuco, Chile.

6. Departamento de Kinesiología, Universidad Católica del Maule, Talca, Chile.

Address for correspondence: Avenida Francisco Salazar \# 01145, Universidad de La Frontera, Temuco Chile.

Rodrigo Muñoz Cofré.

Telephone: +56452596550 - Mobile: +56978970129

E-mail: b.munoz13@ufromail.cl

https://orcid.org/0000-0001-5690-8956 


\section{ABSTRACT}

2

3 Background and objective: Type 2 diabetes mellitus (DM2) and breast cancer (BC) are

4 diseases of high prevalence worldwide. Both alter lung function separately. So suffering

5 both tables would increase this decrease in lung function. The objetive was to determine the

6 effects of DM2 and BC on ventilation volumes and pressures in adult women.

7 Material and Methods: Forty-two women patients were recruited, of whom 40 were

8 accepted under the exclusion criteria. They were divided into four groups: control group

9 (CG), DM2, BC and DM2+BC. Body plethysmography was used to measure forced vital

10 capacity, lung volumes, airway resistance and muscle pressures. Finally the normality of

11 the data was determined using Student's t test or the Mann-Whitney U test; the threshold of

12 significance was $p<0.05$.

13 Results: No significant differences were observed in the anthropometric variables between

14 the control group and the other groups. The ventilation flows showed no significant

15 differences, while the lung volumes presented significant differences in the inspiratory

16 capacity (IC) variables $(\mathrm{p}<0,002)$. Maximum inspiratory and expiratory pressures (MIP-

17 MEP) also presented significant diminution ( $\mathrm{p}<0,001 ; \mathrm{p}<0,041$, respectively).

18 Conclusions: From the results obtained we can conclude that the combination of type 2

19 diabetes mellitus with breast cancer caused a diminution in ventilation volumes and

20 pressures, specifically in IC, MIP and MEP.

21

22 Keywords: diabetes mellitus, breast cancer, pulmonary volumes. 


\section{INTRODUCTION}

26

27 Diabetes mellitus has been rising world-wide. According to figures from the International 28 Diabetes Federation, 425 million people presented diabetes during 2017 and a figure of 29 around 629 million cases is projected for 2045 [1]. Progression of the symptoms is slow 30 and a large number of people suffer the pathology for many years without being diagnosed;

31 it is estimated that 1 out of 2 adults is in this situation [1,2].

32

33 The figures published by the World Health Organization (WHO) for 2012 recorded 8.2 34 million deaths due to cancer and 14.1 million new cases of this pathology in the whole 35 world. In this context, breast cancer is the second most common type in the world and the 36 most frequent in women, with an incidence of 1.67 representing $25 \%$ of all cancers in this 37 population [3].

39 A strong association has been observed between the increase of comorbidities and diabetes

40 sufferers [4]. One example of this is the fact that patients with diabetes are at greater risk of 41 breast cancer [5,6]. In this situation, diabetes is able to promote more rapid tumour growth 42 mediated by hyperglycemia, insulin resistance and hyperinsulinemia [7,8]. All these events 43 may predispose women with diabetes to a greater risk of more advanced breast cancer at 44 the moment of diagnosis.

46 Diabetes causes various microvascular complications attributable to biochemical and 47 structural changes in the proteins of the basal membrane of different organic systems. 48 Specifically, at the alveolar level it restricts lung volumes and capacities [9]. This 
49 functional deterioration has been found principally through transversal associations

50 between the state of the patient's diabetes and measurements of forced vital capacity (FVC)

51 and forced expiratory volume in the first second $\left(\mathrm{FEV}_{1}\right)$; reductions have been found in

52 these variables in association with type 1 and type 2 diabetes [10]. Furthermore, autonomic

53 neuropathies affecting the phrenic nerves have been found, resulting in a reduction of

54 muscular tone and diaphragm control [11].

55

56 At the same time, the use of radiotherapy and/or chemotherapy in addition to medical

57 treatment are fundamental for the treatment of breast cancer. The former consists in local

58 treatment to try to destroy the cancerous cells by the application of external or internal

59 radiation [12]. In the latter, medications are administered which have a variety of secondary

60 effects, particularly dyspnea [13,14]. In general, these treatments cause pneumonitis and

61 fibrosis, which have an impact on lung function [15]. Verbanck et al. (2012) evaluated the

62 acute effects on the respiratory function associated with conventional radiotherapy in 26

63 breast cancer patients at the start of treatment and after 3 months; they observed a

64 significant reduction in the $\mathrm{FEV}_{1}$, the $\mathrm{FVC}$ and the free diffusion of carbon monoxide 65 (FDCO) [16].

66

67 As diabetes and breast cancer produce different effects on lung function, as shown

68 separately, we hypothesised that patients with both pathologies present a poorer lung

69 function than patients who present only one of these conditions. The object of the present

70 study was therefore to determine the effects of breast cancer and type 2 diabetes mellitus on

71 ventilation volumes and pressures in women in the city of Talca. 


\section{3}

74

75 Study design: Analytical cross-sectional cohort study in which a non-probabilistic sample

\section{MATERIALS AND METHODS}

76

77

\section{8}

79

80

81

82 was selected by subject convenience, subject to inclusion and exclusion criteria.

Patients: Forty women of the Maule Region, Chile, with diagnosis of diabetes mellitus and/or breast cancer, with both pathologies being treated currently. The sample was divided into four groups of 12 women each: control (CG), diabetes mellitus (DM2), breast cancer (BC) and diabetes mellitus plus breast cancer $(\mathrm{DM} 2+\mathrm{BC})$. The women in the $\mathrm{CG}$ were selected from the Geriatrics Service of the Talca Hospital, Chile, where they attended for Preventive Health Check-ups. The women in the DM2 group had a certified diagnosis of type 2 diabetes mellitus, were being controlled by the Internal Medicine Service of the Talca Hospital and were undergoing treatment with metformin in doses of 500 to 750 $\mathrm{mg} / \mathrm{day}$. The patients in the BC group were being treated at the Oncology Service of the same hospital. They presented diagnosis of stage IIA to IIIc BC, bilateral or unilateral radical mastectomy and were undergoing adjuvant treatment, starting chemotherapy with doxorubicin, cyclophosphamide and paclitaxel two weeks after the mastectomy, and radiotherapy with doses of 50 Gy six weeks after the surgical procedure. For the DM2+BC group, patients were selected who met the above inclusion criteria for the DM2 and BC groups concomitantly. The exclusion criteria were: not presenting a chronic or acute respiratory disease at the time of evaluation, not being a habitual smoker, not presenting deformities in the thorax (Figure 1). The confounding variables (age, weight, height and body mass index) were contrasted with a statistical method to determine differences between the groups and ensure comparability (Table 1). This study forms part of a Lung 
97 Function Evaluation Project of the Physiotherapy Department which has been approved by

98 the Scientific Ethics Committee of Universidad Católica del Maule (resolution 23/2016).

100 Evaluation of lung function: Measurements in all the tests followed the norms of the 101 American Thoracic Society (ATS). Once the subject's age, height (SECA®220) and 102 bodyweight (SECA® 840) had been recorded, she remained sitting quiet and relaxed for at 103 least 10 minutes before the evaluation. The tests were carried out by a trained operator 104 using a body plethysmograph (Mediagraphics, Model Platinum Elite DL®).

105

106 Forced Vital Capacity: Briefly, the patient ventilated through the pneumotachograph with 107 normal volume for five respiratory cycles; she was then told to carry out a maximum 108 inspiratory manoeuvre followed by maximum forced expiration. The best test out of a 109 minimum of three acceptable and reproducible manoeuvres was selected [17].

111 Measurement of the maximum inspiratory and expiratory pressures (MIP-MEP): To 112 evaluate the MIP, the nose clip was placed on the patient's nose. She ventilated to normal 113 volume for five respiratory cycles through the mouthpiece and was then asked to carry out 114 maximum expiration; the pneumotachograph was blocked and she was asked to carry out 115 maximum inspiration against the closed valve. For the MEP, the instruments were placed in 116 the same position. The patient ventilated to normal volume for five respiratory cycles 117 through the mouthpiece and was then asked to carry out maximum inpiration; the 118 pneumotachograph was blocked and she was asked to carry out maximum expiration 119 against the closed valve. In each case, the best test out of a minimum of three acceptable 120 and reproducible manoeuvres according to current norms was selected [18]. 
122 Ventilation volumes: The mouthpiece was adjusted to the patient's height. The patient had 123 to ensure that her mouth remained engaged with the mouthpiece during the test to avoid air 124 leakage; this was done by holding her facial muscles with her hands during the evaluation. 125 Then the cabin was closed and the patient was asked to carry out four ventilations at normal 126 volume. She was instructed to "pant gently", trying to move volumes of between 50 and 60 $127 \mathrm{~mL}$. The requested panting frequency was around 60 per minute $(1 \mathrm{~Hz})$. The professional in 128 charge activated the shutter for 2 to 3 seconds, then told the patient to to take a maximum 129 inspiration followed by expiration to residual volume (RV)[19].

131 Analysis: The results were analysed using Excel (Microsoft Office, 2010) to tabulate the 132 data and Graph Pad Prism 6® (GraphPad Software Inc., 1995-2015) for statistical analysis; 133 the data were presented as means with standard deviation. The first statistical process was 134 to determine the normality of the data using the Shapiro-Wilk test. Comparisons were 135 carried out using ANOVA or the Kruskal Wallis test; Tukey's test or Dunn's test were used 136 respectively to analyse the difference between variables. The level of significance was $137 \quad p<0.05$.

\section{RESULTS}

141 Of the 50 patients selected, 48 met the criteria for inclusion in the study, CG: $\mathrm{n}=12$, DM2: $142 \mathrm{n}=12, \mathrm{BC}: \mathrm{n}=12, \mathrm{DM} 2+\mathrm{BC}: \mathrm{n}=12$. Two patients were excluded as habitual smokers (Figure 143 1). No significant differences were observed in age $(p=0,704)$, weight $(p=0,052)$, height $144(\mathrm{p}=0,278)$ or body mass index $(\mathrm{BMI})(\mathrm{p}=0,361)$ between the groups (Table 1$)$. In the 
145 evaluation of lung function, the lung flows presented no significant differences (Table 2).

146 The MIP presented significant differences between CG and DM2 ( $<<0,01)$, and similar

147 differences were observed between $\mathrm{CG}$ and $\mathrm{BC}(\mathrm{p}<0,01)$ and between $\mathrm{CG}$ and $\mathrm{DM} 2+\mathrm{BC}$

148 ( $\mathrm{p}<0,01)$. The MEP only presented significant differences between $\mathrm{CG}$ and $\mathrm{DM} 2+\mathrm{BC}$

$149(\mathrm{p}<0,05)$ (Table 3). Significant differences in lung volumes were only found in the IC,

150 where there were significant differences between CG and DM2 ( $<<0,05)$, between BC and

$151 \mathrm{DM} 2+\mathrm{BC}(\mathrm{p}<0,01)$ and finally between $\mathrm{CG}$ and DM2+BC $(\mathrm{p}<0,05)$ (Figure 2).

\section{DISCUSSION}

155 The object of this investigation was to observe the behaviour of lung pressures and volumes

156 when two currently frequent conditions are associated, namely DM2 and BC. The results

157 obtained enabled us to observe that patients with both conditions (DM+BC) suffer a 158 significant diminution of MIP, MEP and IC compared to the CG. There are two reasons 159 why this is important: i) There is a direct relation between lung pressure and volume, so a 160 higher MIP suggests an increased IC and vice-versa, consistent with the results obtained 161 (Figure 2) [20]; and ii) The IC is recruited in activities outside everyday behaviours. It is 162 known that the increase in ventilation demand is sustained by the IC, so any reduction 163 translates into a fall in the maximum oxygen consumption during maximum effort tests 164 with resulting appearance of dyspnea [21].

166 The MIP and MEP of the DM2 group were lower than those of the CG. This agrees with 167 the findings reported by Fuso et al. (2015), who monitored lung function associated with 168 glycemia control (GC) in subjects with DM2 by measuring baseline lung volumes and 
169 pressures, and the values after 3 months of GC. They observed that the MIP diminished in 170 patients with poor GC, and increased in those with good GC; however the difference 171 between the two groups was not significant $(p=0.091)$. The MEP diminished both in 172 patients with poor GC and those with good GC; again the difference between the two 173 groups was not significant $(p=0.719)$ [22]. The results obtained also showed a diminution 174 of the MIP and MEP of the BC group in comparison with the CG, however this was not 175 significant. In contrast, Dos Santos et al. (2013) studied the effect of radiotherapy in BC on 176 lung function, assessing 20 women before and after treatment; they determined that there 177 was a significant diminution of MIP and MEP at the end of the period [23]. Likewise, 178 O'Donnell et al. (2016) found a significant diminution in the MIP of women with BC as 179 compared to the control group [24]. In this context, we note two important facts: i) The 180 behaviour of MEP differs from that of MIP, for which statistical differences were only 181 observed in the CG. This is due to the double function of the abdominal muscles, which are 182 a fundamental part of the coughing mechanism [25] - their tone fluctuates constantly 183 depending on posture [26]; and ii) the results obtained for MIP-IC presented a diminution 184 which expresses the proposed relation between them, supported by the observations of 185 Fadil et al. (2015), who determined a parallel reduction between pressures and volumes in 186 subjects with DM2 [27]. Investigations in mice with DM showed diminished capillarisation 187 and angiogenesis in the skeletal muscle, resulting in smaller fibre size and muscle belly; in 188 the long term these alterations will generate a reduction in muscle functioning [28]. 189 Another important phenomenon which is relevant in this context is the existence of diabetic 190 neuropathy; this condition diminishes muscle mass significantly compared to subjects with 191 neuropathies but who do not suffer DM. The association of neuropathy with diabetes 192 accelerates the process of muscular atrophy [29]. 
194 Specifically, muscular atrophy in DM derives from a diminution in everyday activity and 195 deregulation in the protein synthesis pathway. This is because energy storage and the 196 mitochondrial function are reduced, accelerating the loss of muscle proteins. At the same 197 time, defects in some substrates of the insulin receptor (IRS)-1/phosphatidylinositol-kinase 198 (PI3K) would lead to a reduction in the daily glucose consumption and insulin use by the 199 tissues. This would increase the degradation and diminution of muscle protein synthesis via 200 PI3K/Akt [30]. Furthermore, it has been shown that cancer increases insulin resistance, 201 aggravating this lower activity in the protein synthesis pathways [31]. We hypothesise that, 202 in addition to this mechanism, the increase in RV may also contribute to this diminution in 203 MIP. It is known that increased RV provokes a diminution in the IC and a lowering of the 204 diaphragmatic cupula [20]; this creates an inappropriate environment for generation of 205 force by the diaphragm, limiting its capacity for incursion. Although the results obtained do 206 not show significant differences in the RV, an increased value is observed in the DM2+BC 207 group. This agrees with the findings reported by Connolly and Mittendorfer, who say that 208 ultrasound allows diaphragm dysfunctions to be measured in real time through diaphragm 209 movement; ultrasound can also give an idea of muscle inspiratory pressure, as subjects with 210 a smaller change in amplitude between inspiration and expiration in tranquillity would have 211 a smaller diaphragmatic force [32]. This also correlates with lung function, specifically 212 with the RV; an increase of the latter is associated with a diminution in the amplitude of 213 change of the diaphragmatic cupula [33]. We assume this as a limitation of this study; at the 214 same time, we raise the question of how to determine the real contribution of the two 215 mechanisms to the diminution of MIP in patients with DM2+BC. 
217 Lecube et al. (2010), investigating the assessment of lung volumes, explored the lung

218 function in obese women with DM and found that patients with both conditions presented a

219 significant diminution in $\mathrm{VEF}_{1}$ and $\mathrm{RV}$ in comparison with obese women without DM.

220 Furthermore, they showed no significant differences in total lung capacity (TLC) [34]; in

221 this context, measurement of muscular force by MIP and MEP would have complemented

222 the results reported and explained them better. Fadil et al. (2015) studied 45 men with

223 DM2, finding a significant diminution in TLC as compared to CG [27]. The results

224 obtained show a similar decline in lung capacities, specifically the IC of patients with DM

225 which was not significant; however this variable was significantly smaller than the CG

226 when the condition of BC was added (Figure 1). The evidence indicates that the IC is

227 equivalent to between 50 and $60 \%$ of the TLC and that both are sensitive to restrictive

228 patterns; this is important if we consider that Sreeram (2016), in a study of 90 subjects with

229 DM2, showed the existence of a restrictive pattern in 55\% of the cases [35].

231 The IC reached its lowest value in the $\mathrm{DM}+\mathrm{BC}$ group. In this context, $\mathrm{BC}$ would also

232 influence this variable; thus when the evidence concerning DM is examined, it is important

233 to examine also the effects of BC on lung function. In this context, Muñoz et al. (2019), in

234 a population of patients similar to that of the present study, showed that the IC was reduced

235 in women with BC treated with chemotherapy and radiotherapy concomitantly [36].

236 O'Donnell et al. (2016) measured the behaviour of $\mathrm{VO}_{2 \max }$ and the lung function in patients

237 with $\mathrm{BC}$, finding a significant diminution in the percentage of the predicted IC of these

238 patients versus the control group [24]. This result disagrees with the findings of the present

239 investigation, where no significant differences were observed in this variable. However we

240 did observe significant differences between BC and DM. Likewise, when BC is combined 
241 with DM, a significant diminution was found compared to the CG, and we therefore

242 attribute this greater diminution to the sum of the two conditions. This indicates that there

243 are two phenomena acting in parallel on the respiratory system: on the one hand DM,

244 which, as explained above, diminishes muscle mass and strength [28]; and on the other

245 cancer and its treatment, which provoke various alterations in the ventilation system such as

246 loss of pneumocytes and tensioactive agent, and the appearance of oedema in the basal

247 membrane [23]. These changes in conjunction would reinforce one another, generating a

248 greater diminution of IC as compared to the other groups.

251 Among the limitations of this investigation, we recognise that the patients were not 252 evaluated for dyspnea and physical activity. In this context, we believe that it would be 253 very advantageous for future investigations to apply scales to objectify this symptom, 254 complemented with the six minute walking test to determine its relation with IC. The 255 standardisation of the cancer patients was not regulated, as there were patients in the BC 256 and DM2+BC groups both with and without radiotherapy. From the results obtained we can 257 conclude that the combination of type 2 diabetes mellitus with breast cancer caused a 258 diminution in ventilation volumes and pressures, specifically in IC, MIP and MEP.

260 Author Contributions: Conceptualization: R.M.C., G.P.R., W.V.A., M.E.C; methodology:

261 R.M.C, M.D.S., M.E.C; software: G.M.N., D.C.V., W.V.A., G.P.R.; validation: R.M.C., 262 G.P.R., W.V.A., M.E.C.; formal analysis: R.M.C, M.D.S., M.E.C, G.M.N., D.C.V; 263 investigation: R.M.C, M.D.S., M.E.C, D.C.V; data curation: G.M.N, R.M.C; writing- 
264 original draft preparation: R.M.C, D.C.V, M.E.C; supervision: R.M.C; project 265 administration: R.M.C.

266 Funding: This research received no external funding.

267 Acknowledgements: We thank: all participants included in the cohort study for their kind 268 participation in this research

269 Conflicts of Interest: The authors declare no conflict of interest.

270

271

272

273 REFERENCES

274

275 1. International Diabetes Federation. Diabetes Atlas, 8 ${ }^{\text {th }}$ edition. 2017. Available 276 online: http://www.diabetesatlas.org/across-the-globe.html. (accessed on 9 May 277 2019).

278

2. GLOBOCAN 2012. International Agency for Research on Cancer. Estimated Cancer Incidence, Mortality and Prevalence Worldwide in 2012. Available online: http://globocan.iarc.fr/old/FactSheets/cancers/breast-new.asp. (accessed on 9 May, 2019).

3. Alonso-Morán, E.; Orueta, J.F.; Fraile Esteban, J.I.; Arteagoitia Axpe, J.M.; Marqués González, M.L.; Toro Polanco, N.; Ezkurra Loiola, P.; Gaztambide, S.; Nuño-Solinis, R. The prevalence of diabetes-related complications and multimorbidity in the population with type 2 diabetes mellitus in the Basque Country. BMC Public Health. 2014, 14, 1059. 
4. Griffiths, R.I.; Danese, M.D.; Gleeson, M.L.; Valderas, J.M. Epidemiology and outcomes of previously undiagnosed diabetes in older women with breast cancer: an observational cohort study based on SEER-Medicare. BMC Cancer. 2012, 12, 613.

5. Lipscombe, L.L.; Fischer, H.D.; Austin, P.C.; Fu, L.; Jaakkimainen, R.L.; Ginsburg, O.; Rochon, P.A.; Narod, S.; Paszat, L. The association between diabetes and breast cancer stage at diagnosis: a population-based study. Breast Cancer Res. Treat. 2015, 150, 613-20.

6. Hernandez, A.V.; Guarnizo, M.; Miranda, Y.; Pasupuleti, V.; Deshpande, A.; Paico, S.; Lenti, H.; Ganoza, S.; Montalvo, L.; Thota, P.; Lazaro, H. Association between insulin resistance and breast carcinoma: a systematic review and meta-analysis. PLoS One. 2014, 9, e99317. 110.

8. Chance, W.W.; Rhee, C.; Yilmaz, C.; Dane, D.M.; Pruneda, M.L.; Raskin, P.; Hsia, C.C. Diminished alveolar microvascular reserves in type 2 diabetes reflects systemic microangiopathy. Diabetes Care. 2008, 31, 1596-601.

9. Klein, O.L.; Krishnan, J.A.; Glick, S. Systematic review of the association between lung function and Type 2 diabetes mellitus. Diabet. Med. 2010, 27, 977-87. endurance in type 2 diabetes mellitus. Diabetes Metab. Res. Rev. 2012, 28, 370-5.

11. American Cancer Society. Radiation for Breast Cancer. 2017. Available online: https://www.cancer.org/cancer/breast-cancer/treatment/radiation-for-breastcancer.html. (accessed on 9 May 2019). 
311
12. American Cancer Society. Chemotherapy for Breast Cancer. 2017. Available online: https://www.cancer.org/cancer/breast-cancer/treatment/chemotherapy-forbreast-cancer.html. (accessed on 9 May, 2019).

13. Dimopoulou, I.; Galani, H.; Dafni, U.; Samakovii, A.; Roussos, C.; Dimopoulos, M.A. A prospective study of pulmonary function in patients treated with paclitaxel and carboplatin. Cancer. 2002, 94, 452-8.

14. Muñoz, R.; del Sol, M.; Palma, G.; Valverde, W.; Conei, D.; Marzuca-Naser, G.; Medina, P.; Escobar, M. Efecto del estado nutricional y cáncer de mamas sobre los volúmenes pulmonares. Nutr. Hosp. 2019, 36, 428-33.

15. Verbanck, S.; Hanon, S.; Schuermans, D.; Van Parijs, H.; Vinh-Hung, V.; Miedema, G.; Verellen, D.; Storme, G.; Vanhoeij, M.; Lamote, J.; De Ridder, M.; Vincken, W. Small airways function in breast cancer patients before and after radiotherapy. Breast Cancer Res. Treat. 2012, 135, 857-65.

16. American Thoracic Society. Standardization of spirometry. Eur. Respir. J. 2005, 26, 319-38.

17. American Thoracic Society/European Respiratory Society. ATS/ERS Statement on Respiratory Muscle Testing. Am. J. Respir. Crit. Care. Med. 2002, 166, 518-624.

18. Jiang, G.; Li, A.; Wang, L.; Qian, L.; Cao, Y.; Huang, J.; Wan, C.; Zhang, X. Reference data for Baby Body-plethysmographic measurements in Chinese neonates and infants. Respirology. 2017, 16, 1-8.

19. Lufti, M.F. The physiological basis and clinical significance of lung volume measurements. Multidiscip. Respir. Med. 2017, 12, 3. 
20. Richter, M.J.; Gall, H.; Wittkämper, G.; Seeger, W.; Mayer, E.; Ghofrani, H.A.; Guth, S.; Reichenberger, F. Inspiratory capacity is not altered in operable chronic thromboembolic pulmonary hypertension. Pulm. Cir. 2017, 7, 543-46.

21. Fuso, L.; Pitocco, D.; Condoluci, C.; Conte, E.; Contu, C.; Rizzi, A.; Angeletti, G.; Bibi, B.F.; Antonelli-Incalzi, R. Decline of the lung function and quality of glycemic control in type 2 diabetes mellitus. Eur. J. of Intern. Med. 2015, 26, 27378.

22. Dos Santos, D.E.; Tirolli, M.; Carvalho, A.; Bezerra, T.S.; de Santana, J.S.; da Silva, W. Efeito da radiotherapy na função pulmonar e na fadiga de mulheres em tratamento para o câncer de mama. Fisioter. Pesq. 2013, 20, 50-5.

23. O’Donnell, D.E.; Webb, K.A.; Langer, D.; Elbehairy, A.F.; Neder, J.A.; Dudgeon, D.J. Respiratory Factors Contributing to Exercise Intolerance in Breast Cancer Survivors: A Case-Control Study. J. Pain Symptom Manage. 2016, 52, 54-63.

25. Takakusaki, K.; Chiba, R.; Nozu, T.; Okumura, T. Brainstem control of locomotion and muscle tone with special reference to the role of the mesopontine tegmentum and medullary reticulospinal systems. J. Neural Transm. 2016, 123, 695-729.

24. Costa, R.; Almeida, N.; Ribeiro, F. Body position influences the maximum inspiratory and expiratory mouth pressures of young healthy subjects. Physiotherapy. 2015, 101, 239-41.

6. Fadil, M.A.; Ghaffar, K.A.; Al-Adl, A.S. Respiratory function in type II diabetes mellitus. Egyptian Journal of Chest Diseases and Tuberculosis. 2015, 64, 219-23.

27. D’Souza, D.; Al-Sajee, D.; Hawke, T.J. Diabetic myopathy: impact of diabetes mellitus on skeletal muscle progenitor cells. Front. Physiol. 2013, 20, 379. 
28. Santos, A.J.C.A.; Silva, E.L.A.; Albuquerque, Y.M.L.; Oliveira, B.D.R.; Caiaffo, V. Effects of diabetes mellitus type I on skeletal muscle: an integrative review. $J$. Morphol. Sci. 2016; 33: 118-20.

29. Rudrappa, S.S.; Wilkinson, D.J.; Greenhaff, P.L.; Smith, K.; Idris, I.; Atherton, P.J. Human Skeletal Muscle Disuse Atrophy: Effects on Muscle Protein Synthesis, Breakdown, and Insulin Resistance - A Qualitative Review. Front Physiol. 2016; 7: 361.

30. Johns, N.; Stephens, N.A.; Fearon KC. Muscle wasting in cancer. Int. J. Biochem. Cell. Biol. 2013; 45: 2215-29.

31. Connolly, A.M. \& Mittendorfer, B. Tracking diaphragm movement by using ultrasound to assess its strength. J. Physiol. 2016; 594: 7147-8.

32. Richard, P. Exploring The diaphragm; Ultrasound is essential. Rev. Mal. Respir. 2017; 34: 645-60.

33. Lecube, A.; Sampol, G.; Muñoz, X.; Hernández, C.; Mesa, J.; Simó, R. Type 2 diabetes impairs pulmonary function in morbidly obese women: a case-control

34. Sreeram, G. Correlation of pulmonary function test and duration of type 2 diabetes mellitus. J. Assoc. Physicians India. 2016; 64: 94.

\section{5} study. Diabetologia. 2010; 53: 1210-16.

35. Valverde, W.; Palma, G.; Conei, D.; Muñoz, R.; del Sol, M.; Marzuca-Naser, G.; Medina, P.; Escobar, M. Efectos de la radioterapia y quimioterapia concomitantes sobre los volúmenes pulmonares en mujeres con cáncer de mama de Talca, Chile. 


\section{TABLES}

380

381 Table 1. Description of the control group and patients with breast cancer.

\begin{tabular}{|c|c|c|c|c|c|}
\hline & CG & DM2 & $\overline{B C}$ & DM2+BC & p value \\
\hline $\mathbf{N}$ & 12 & 12 & 12 & 12 & \\
\hline Age (years) & $56 \pm 9$ & $59 \pm 53$ & $61 \pm 9$ & $59 \pm 10$ & 0,704 \\
\hline Weight (kg) & $67.25 \pm 11.35$ & $80.83 \pm 9.17$ & $70.40 \pm 8.12$ & $70.90 \pm 10.37$ & 0,052 \\
\hline Height (cm) & $155.60 \pm 4.66$ & $1.61 \pm 0.09$ & $156.3 \pm 6.12$ & $155.8 \pm 6.66$ & 0,278 \\
\hline BMI $\left(\mathrm{kg} / \mathrm{m}^{2}\right)$ & $27.67 \pm 3.72$ & $30.85 \pm 2.46$ & $28.88 \pm 3.39$ & $29.40 \pm 5.28$ & 0,361 \\
\hline $\begin{array}{l}\text { Origin of cancer } \\
\mathbf{L B}^{\circ} \\
\mathbf{R B}^{\circ} \\
\mathbf{B B}^{\circ}\end{array}$ & & & $\begin{array}{l}5(50) \\
5(50) \\
0(0)\end{array}$ & $\begin{array}{l}5(50) \\
3(30) \\
2(20)\end{array}$ & \\
\hline \multicolumn{6}{|l|}{ Stage of cancer } \\
\hline 0 & & & $1(10)$ & $2(20)$ & \\
\hline I & & & $1(10)$ & $1(10)$ & \\
\hline II A & & & $3(30)$ & $2(20)$ & \\
\hline II B & & & $1(10)$ & $3(30)$ & \\
\hline III A & & & $1(10)$ & $2(20)$ & \\
\hline III B & & & $1(10)$ & $0(0)$ & \\
\hline III C & & & $1(10)$ & $0(0)$ & \\
\hline IV & & & $1(10)$ & $0(0)$ & \\
\hline \multicolumn{6}{|l|}{$\begin{array}{l}\text { Chemotherapy (mean } \\
\text { mg/doses/cycle) }\end{array}$} \\
\hline Doxorubicin & & & $95 / 4 / 4(100)$ & $102 / 4 / 4(90)$ & \\
\hline Cyclophosphamide & & & $991 / 4 / 4(100)$ & $1020 / 4 / 4(90)$ & \\
\hline Paclitaxel & & & 130/9/3 (90) & $159 / 10 / 4(70)$ & \\
\hline \multicolumn{6}{|l|}{$\begin{array}{l}\text { Radiotherapy } \\
\text { (radiation/sessions) }\end{array}$} \\
\hline Dose & & & $50 \mathrm{~Gy} / 25(40)$ & 37 Gy/27 (50) & \\
\hline
\end{tabular}

383 N: number; kg: kilograms; cm: centimetres; kg/m²: kilograms divided by metres squared, 384 LB: left breast; RB: right breast; BB: bilateral. Gy: Gray.

385

386 
390 Table 2. Description of lung flows in the sample studied.

\begin{tabular}{|c|c|c|c|c|c|}
\hline$\overline{\text { Variable }}$ & $\underset{(n=12)}{\mathbf{C G}}$ & $\begin{array}{c}\text { DM2 } \\
(\mathrm{n}=12)\end{array}$ & $\begin{array}{c}\mathrm{BC} \\
(\mathrm{n}=12)\end{array}$ & $\begin{array}{c}\text { DM2+BC } \\
(\mathrm{n}=12)\end{array}$ & p value \\
\hline$\overline{\text { FVC (L) }}$ & $2.94 \pm 0.28$ & $2.57 \pm 0.52$ & $2.93 \pm 0.30$ & $2.54 \pm 0.86$ & 0,074 \\
\hline $\operatorname{FEV}_{1}(\mathbf{L})$ & $2.38 \pm 0.20$ & $2.12 \pm 0.43$ & $2.31 \pm 0.37$ & $2.10 \pm 0.64$ & 0,154 \\
\hline $\mathrm{FEV}_{1} / \mathrm{FVC}(\%)$ & $81.36 \pm 5.03$ & $82.60 \pm 3.68$ & $78.30 \pm 7.16$ & $84.30 \pm 5.27$ & 0,110 \\
\hline FEF $_{25}(\mathrm{~L} / \mathrm{s})$ & $5.12 \pm 0.83$ & $5.44 \pm 1.07$ & $4.98 \pm 1.00$ & $5.42 \pm 1.46$ & 0,092 \\
\hline $\operatorname{FEF}_{75}(\mathrm{~L} / \mathrm{s})$ & $1.14 \pm 0.35$ & $0.87 \pm 0.35$ & $0.90 \pm 0.33$ & $0.91 \pm 0.27$ & 0,235 \\
\hline FEF $_{25-75}(\mathrm{~L} / \mathrm{s})$ & $2.52 \pm 0.62$ & $2.18 \pm 0.60$ & $2.22 \pm 0.76$ & $2.35 \pm 0.56$ & 0,158 \\
\hline FEF max $(\mathbf{L} / \mathbf{s})$ & $5.88 \pm 0.97$ & $5.84 \pm 1.08$ & $5.53 \pm 0.50$ & $5.75 \pm 1.51$ & 0,609 \\
\hline
\end{tabular}

CG: control group; DM2: diabetes mellitus; BC: breast cancer; DM2+BC: diabetes mellitus + breast cancer; FVC: forced vital capacity; $\mathbf{F E V}_{\mathbf{1}}$ : forced expiratory volume in the first second; $\mathbf{F E V}_{\mathbf{1}} / \mathbf{F V C}$ : ratio between the forced expiratory volume in the first second and forced vital capacity; \%: percentage; FEF 25: forced expiratory flow at 25\% of the forced vital capacity; FEF 25-75: forced expiratory flow at between $25 \%$ and 75\% of the forced vital capacity; FEF 75: forced expiratory flow at 75\% of the forced vital capacity; FEF max: maximum forced expiratory flow; L/s: litres divided by seconds; $\mathbf{L}$ : litres; $\mathbf{s}$ : seconds. 
412 Table 3. Description of the lung pressures in the sample studied.

\begin{tabular}{lcllcc}
\hline Variable & $\begin{array}{c}\text { CG } \\
(\mathbf{n = 1 2})\end{array}$ & $\begin{array}{c}\text { DM2 } \\
(\mathbf{n = 1 2})\end{array}$ & $\begin{array}{c}\text { BC } \\
(\mathbf{n = 1 2})\end{array}$ & $\begin{array}{c}\text { DM2+BC } \\
(\mathbf{n = 1 2})\end{array}$ & p value \\
\hline MIP $\left(-\mathbf{c m H}_{\mathbf{2}} \mathbf{O}\right)$ & $77.67 \pm 22.04$ & $66.00 \pm 23.57$ & $73.70 \pm 27.80$ & $58.80 \pm 36.04$ & 0,001 \\
MEP $\left(\mathbf{c m H}_{\mathbf{2}} \mathbf{O}\right)$ & $87.83 \pm 18.27$ & $84.60 \pm 25.98$ & $71.00 \pm 28.64$ & $65.80 \pm 23.95$ & 0,041 \\
\hline
\end{tabular}

$413 \mathbf{C m H}_{2} \mathrm{O}$ : centimetres of water; MIP: maximum inspiratory pressures; MEP: maximum

414 expiratory pressures; CG: control group; DM2: diabetes mellitus; BC: breast cancer;

415 DM2+BC: diabetes mellitus + breast cancer.

416

417

418

419

420

421

422

423

424

425

426

427

428

429

430

431

432

433

434 
435 Table 4. Description of the lung volumes in the control group and patients with breast 436 cancer.

\begin{tabular}{llllll}
\hline Variable & $\begin{array}{c}\text { CG } \\
(\mathbf{n = 1 2})\end{array}$ & $\begin{array}{c}\text { DM2 } \\
(\mathbf{n = 1 2})\end{array}$ & $\begin{array}{c}\text { BC } \\
(\mathbf{n = 1 2})\end{array}$ & $\begin{array}{c}\text { DM2+BC } \\
(\mathbf{n = 1 2})\end{array}$ & p value \\
\hline SVC (L) & $3.10 \pm 0.32$ & $2.59 \pm 0.38$ & $3.07 \pm 0.30$ & $2.55 \pm 0.81$ & 0,062 \\
IC (L) & $2.52 \pm 0.37$ & $2.24 \pm 0.28$ & $2.61 \pm 0.32$ & $2.04 \pm 0.58$ & 0,002 \\
ERV (L) & $0.43 \pm 0.26$ & $0.34 \pm 0.27$ & $0.46 \pm 0.17$ & $0.50 \pm 0.31$ & 0,178 \\
VGT (L) & $3.11 \pm 0.55$ & $2.98 \pm 0.58$ & $3.00 \pm 0.94$ & $3.11 \pm 0.90$ & 0,609 \\
RV (L) & $2.54 \pm 0.37$ & $2.34 \pm 0.59$ & $2.54 \pm 0.90$ & $2.61 \pm 0.94$ & 0,963 \\
TLC (L) & $5.34 \pm 0.54$ & $4.93 \pm 0.58$ & $5.62 \pm 0.90$ & $5.16 \pm 1.16$ & 0,320 \\
RV/TLC & $46.00 \pm 5.42$ & $47.00 \pm 8.08$ & $44.40 \pm 8.12$ & $50.60 \pm 11.49$ & 0,227 \\
\hline RAW (cmH2O/L/s) & $1.17 \pm 0.68$ & $1.64 \pm 0.64$ & $1.50 \pm 1.20$ & $0.89 \pm 0.40$ & 0,467 \\
GAW (L/s/cmH2O) & $1.17 \pm 0.69$ & $0.68 \pm 0.22$ & $0.95 \pm 0.51$ & $1.38 \pm 0.72$ & 0,065 \\
SRAW (cmH2O*s) & $4.39 \pm 2.68$ & $5.44 \pm 1.94$ & $4.97 \pm 2.75$ & $2.96 \pm 1.05$ & 0,059 \\
SGAW (1/cmH $\mathbf{c O}$ *s) & $0.33 \pm 0.22$ & $0.20 \pm 0.07$ & $0.25 \pm 0.12$ & $0.35 \pm 0.11$ & 0,072
\end{tabular}

437 SVC: slow vital capacity; IC: inspiratory capacity; ERV: expiratory reserve volume; RV: 438 residual volume; TLC: total lung capacity; L: litres; RV/TLC: residual volume divided by 439 total lung capacity; RAW: airway resistance; GAW: airway conductance; $\mathbf{R A W}$ : specific 440 airway resistance; $\mathbf{S G A W : ~ s p e c i f i c ~ a i r w a y ~ c o n d u c t a n c e ; ~} \mathbf{c m H 2 O} / \mathbf{L} / \mathbf{s}$ : centimetres of water 441 divided by litres divided by seconds; $\mathbf{L} / \mathbf{s} / \mathbf{c m H} \mathbf{m}_{2} \mathbf{O}$ : litres divided by seconds divided by 442 centimetres of water; $\mathbf{c m H}_{\mathbf{2}} \mathbf{O} * \mathbf{s}$ : centimetres of water per second; $1 / \mathbf{c m H}_{\mathbf{2}} \mathbf{O} * \mathbf{s}$ : one divided 443 by centimetres of water per second.

444

445

446

447

448

449

450

451

452

453 
456 Figure 1. Flow chart of recruitment and measurements of the four groups designated

457

458 Figure 2. Behaviour of airway pressures and volumes and statistical differences in the 459 sample studied.

460

461

462 **: $\mathrm{p}<0.01 ; *: \mathrm{p}<0.05$. MIP: maximum inspiratory pressures; MEP: maximum expiratory 463 pressures; IC: inspiratory capacity; $\mathbf{c m H}_{2} \mathbf{O}$ : centimetres of water; L: litres; $\mathbf{C G : ~ c o n t r o l}$ 464 group; DM2: diabetes mellitus; BC: breast cancer; DM2+BC: diabetes mellitus + breast 465 cancer. A. Maximum inspiratory pressure; B. Maximum expiratory pressure; C. Inspiratory 466 capacity.

467

468 
Figure 1. Flow chart of recruitment and measurements of the four groups designated

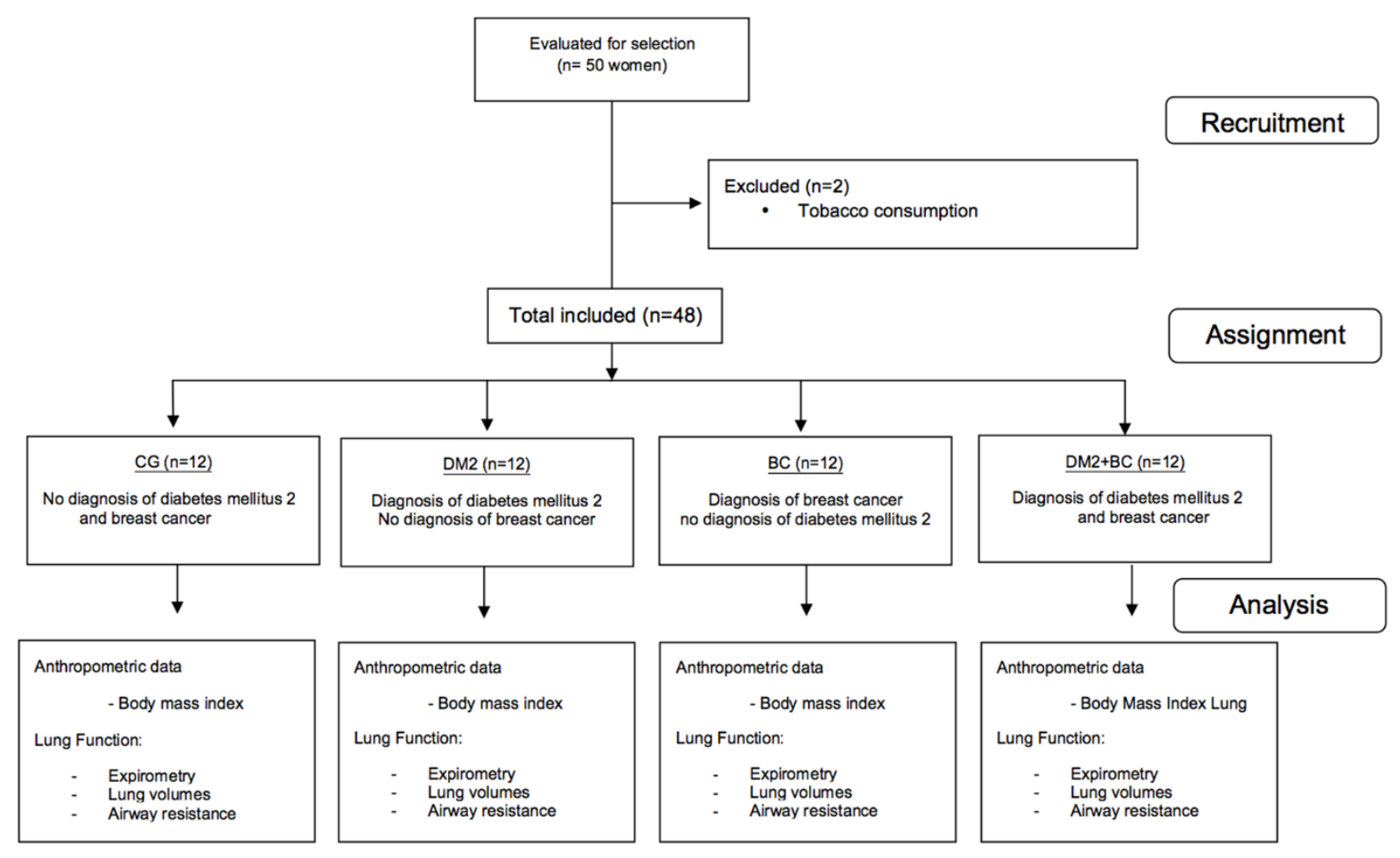


Figure 2. Behaviour of airway pressures and volumes and statistical differences in the sample studied.
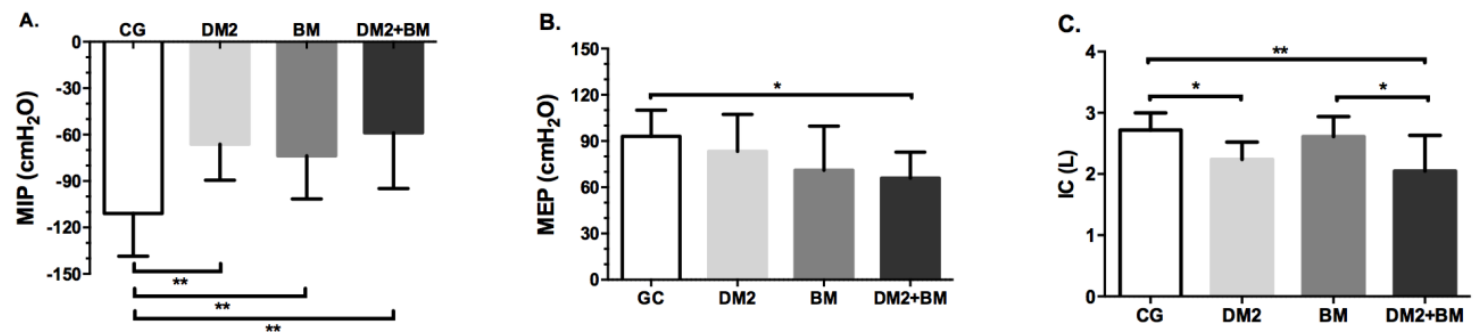

**: $\mathrm{p}<0.01$; $: \mathrm{p}<0.05$. MIP: maximum inspiratory pressures; MEP: maximum expiratory pressures; IC: inspiratory capacity; $\mathbf{c m H}_{2} \mathrm{O}$ : centimetres of water; L: litres; CG: control group; DM2: diabetes mellitus; BC: breast cancer; DM2+BC: diabetes mellitus + breast cancer. A. Maximum inspiratory pressure; B. Maximum expiratory pressure; C. Inspiratory capacity. 